\title{
FREQUENCY AND DISTRIBUTION OF IMMUNOGLOBULIN CONTAINING PLASMA CELLS IN ILEUM REPRESENTING GUT-ASSOCIATED-LYMPHATIC TISSUES IN THE BCRDV-VACCINATED BROILER
}

\author{
M. A. Masum ${ }^{1,2^{*}}$, M. Z. I. Khan ${ }^{1,3}$ M. N. H. Siddiqi ${ }^{1}$, M. Nasrin ${ }^{1}$ and N. Sultana ${ }^{1}$. \\ ${ }^{1}$ Department of Anatomy and Histology, Faculty of veterinary Science, Bangladesh Agricultural University, \\ Mymensingh, Bangladesh. \\ ${ }^{2}$ Department of Anatomy, Histology and Physiology, Faculty of Animal Science and Veterinary Medicine, \\ Sher-e-Bangla Agricultural University, Dhaka, Bangladesh. \\ ${ }^{3}$ Faculty of Veterinary Medicine, University Malaysia Kelantan, Locked Bag 36, Pengkalan Chepa, 16100 Kota \\ Bharu, Kelantan, Malaysia.
}

\begin{abstract}
Histological studies and development of immunoglobulin containing plasma cells in ileum representing gut-associatedlymphatic tissue of various group of broiler chickens vaccinated with Baby Chick Ranikhet Disease Vaccine (BCRDV) was carried out in the Department of Anatomy and Histology, Bangladesh Agricultural University, Mymensingh during January to October, 2011. A total of 24 day-old broiler chickens of both sexes were divided into two groups such as vaccinated and control. Vaccinated group of broiler chickens were vaccinated at third day through ocular route. It was observed that the villi of ileum were long and slender, lined by simple columnar cells with numerous goblet cells. Scattered lymphocytes and unorganized lymphatic nodules were present in the lamina propria and core of the villi. The frequency and distribution of lymphocytes in the lamina propria and intraepithelial lymphocytes were increased with concentration in vaccinated group. The length and width of mucosa were highest at $\mathrm{D}_{28}$. In the ileum of chickens, the $\operatorname{IgA}$, IgG and IgM positive cells were found in the lamina propria, around the intestinal glands and in the core of the villi of both control and vaccinated group of chickens. The IgA positive cells were significantly $(\mathrm{p}<0.01)$ higher than IgG and IgM positive cells in all stages of study in each group of chickens.
\end{abstract}

Key words: Immunoglobulin, plasma cell, ileum, lymphatic tissue, broiler and BCRDV vaccine.

\section{INTRODUCTION}

Poultry production especially chickens and ducks has attained an important place in agricultural economy of Bangladesh both through contribution to GDP and employment especially in urban and pre-urban areas. However, the viral disease such as New castle disease (Ranikhet), respiratory diseases, vitamin deficiency creating major constraints in developing the poultry farms in Bangladesh. The freedom from disease is dependent on the existence of a complex and highly sophisticated defense system, called lymphoid system (Cortan, 1988). The digestive tract of chicken is the major site of antigenic challenge in the body, being continuously exposed to antigens and commensal bacteria, (Mowat and Viney, 1997). To deal with these challenges the mucosa is populated by a significant proportion of the overall cellular population of the immune system. These lymphoid tissues, usually known as Mucosa-Associated-Lymphatic tissue (MALT) which contains a large number of immune cells of various types, including T lymphocytes, B lymphocytes, plasma ce11s, macrophages, dendritic cells and antigen presenting cells (APCs) (McDonald and Spencer, 1994).

The plasma cells are the cells of the immune system that secrete large amounts of antibodies (McGhee et al., 1997). They differentiate from B cells upon stimulation by an antigen and are the principal effector cells involved in humeral immunity. These immunoglobulin (Ig) containing plasma cells are distributed in the lamina propria of the respiratory tract, digestive tract (Jeurissen et al.,1989), genital tract (Khan et al., 1997) and lymphoid organs (Khan et al., 1998b). The mucosal epithelia of mammals and chickens contain different types of migrating immunocompetent cells, such as globule leukocytes (GIs), lymphocytes, macrophages and plasma cells. Through these cells, mucosal immune system plays important role in the defense activities against microorganisms. Now-a-days, in order to protect New castle disease, various commercial vaccines are used by the broiler farmers. However, vaccine's individual effectiveness, especially in generation, mobilization and distribution of the immunocompetent cells (lymphocytes and IgA, IgG and IgM-containing plasma cells) in mucosal organs is not clear.

*Corresponding e-mail address: masum_dvmru@yahoo.com

Copyright (C) 2012 Bangladesh Society for Veterinary Medicine

All rights reserved 0240/2012 


\section{A. Masum and others}

Through this present study, knowledge about the kinetics and immunoglobulins class distribution of an antibody response in the gut-associated-lymphatic tissues might enlarge our understanding of the induction and effector phase of BCRDV vaccine. It will eventually provide new information to develop and evaluate vaccines and to optimize vaccine application.

\section{MATERIALS AND METHODS}

The experiment was carried out in the Department of Anatomy and Histology, Faculty of Veterinary Science, Bangladesh Agricultural University, Mymensingh. A total 24 day-old "Cob-500" broiler chickens of both sexes were purchased from "Kazi Farm Ltd." Mymensingh. The chickens were divided into two groups such as vaccinated group (each of 12 broilers) and control group (each of 12 broilers). The chickens had no developmental disorders and detectable diseases that may influence in the distribution of lymphocytes and plasma cells containing different classes of immunoglobulins (IgA, IgG and IgM) in ileum which represent gutassociated- lymphoid tissues of broiler. The chickens were reared in a litter system in a poultry shed of the Department of Poultry Science, Faculty of Animal Husbandry, Bangladesh Agricultural University, Mymensingh. Bio-security of the poultry shed was maintained strictly and brooding management was also strictly followed. Optimum temperature, lighting and ventilation were maintained in the brooder. At day 3 , BCRDV vaccine was administered through intraocular route for the prevention of Baby Chick Ranikhet Disease. For histological and immunohistochemical staining purpose, ileum was collected, after sacrificing the chickens through cervical subluxation method. First, second and third sample was collected from both vaccinated and control group at Day $1\left(\mathrm{D}_{1)}\right.$, Day14 $\left(\mathrm{D}_{14}\right)$ and Day $28\left(\mathrm{D}_{28}\right)$ respectively. For histological studies, the samples were collected, cut into pieces, and then fixed in the "Bouin's fluid" (Gridley, 1960) for 12 hours. The selected samples were dehydrated in a series of ascending grades of alcohol $(70 \%, 80 \%, 95 \%$ and $100 \%)$, cleared in several changes of xylene, and infiltrated with different grades of melted paraffin in the oven at $52^{\circ} \mathrm{C}$. The tissues were then embedded in liquid paraffin and finally the sections were cut at $6 \mu \mathrm{m}$ thickness using sliding microtome (MIC 509, Euromex, Japan). After sectioning, the sections were floated on luke warm water in a floatation bath at $37^{\circ} \mathrm{C}$ for stretching, then the sections were attached on cleaned glass slides using egg albumin and then dried. The sections were then deparaffinized first in several changes of xylene followed by rehydration in a series of descending grades of alcohol $(100 \%, 95 \%, 80 \%$ and $70 \%)$. The sections were dipped in Hematoxylin (basophilic dye) for 10-15 minutes (as required) and Eosin (acidophilic dye) for 2-4 minutes (as required) (Gridley, 1960). After staining, the sections were dehydrated again in a series of ascending grades of alcohol (70\%, 80\%, 95\%, and 100\%), cleared in xylene and mounted with "DPX".

The antibodies for detecting immunoglobulin (Igs)-positive cells used in this experiment were normal rabbit serum (Biosource Camarillo, CA), goat anti-chicken IgA (Bethyl Lab, goat anti-chicken IgG (Bethyl Lab, TX), goat anti-chicken IgM (Bethyl Lab) and HRP-conjugated rabbit anti-goat IgG (Bethyl Lab). For immunohistochemical studies, the tissues were fixed in Bouin's fluid and were embedded in paraffin according to the conventional method. Paraffin sections of $6 \mu \mathrm{m}$ in thickness were immunostained by the indirect immunoperoxidase method. In brief, after endogenous peroxidase was inhibited with methanol and hydrogen peroxide $\left(\mathrm{H}_{2} \mathrm{O}_{2}\right)$, the sections were overlayed with $2 \%$ normal rabbit serum diluted with $0.01 \mathrm{M}$ phosphate buffered saline (PBS) for 2 hours, followed by incubation with goat anti-chicken IgG (1:1000) (Bethyl Lab. Inc. USA), goat anti-chicken IgA $(1: 1000)$ or goat anti-chicken IgM $(1: 1000)$ for 18 hours at $4^{\circ} \mathrm{C}$. After a short washing with phosphate buffered saline (PBS), sections were treated with $1 \%$ peroxidase-conjugated rabbit antigoat $\mathrm{IgG}(1: 1000)$ for 2 hours at room temperature. The positive reactions for different classes of Igs were revealed by treating the sections with $0.2 \mathrm{mg} \mathrm{3,3'-diamino-benzidine} \mathrm{tetrahydrochloride} \mathrm{dehydrate} \mathrm{(DAB)}$ (AppliChem, Darmstadt) per ml of Tris-hydrochloride $\left(0.05 \mathrm{M}, \mathrm{pH}\right.$ 7.6) containing $0.03 \% \mathrm{H}_{2} \mathrm{O}_{2}$ and then counterstained few dips with hematoxylin.

The immunopositive cells (Igs) in the ileum were counted in the lamina propria and in the core of the villi where the Igs-positive cells were uniformly distributed. All values were expressed as Mean $\pm \mathrm{SE}$ Statistical significance of difference between three stages were evaluated by using paired sample t-test. All statistical analyses were done by using Statistical Package for Social Science (SPSS 15). 
Frequency and distribution of immunoglobulin containing plasma cells

\section{RESULTS AND DISCUSSION}

In the present study, histological examination revealed that the ileum was a tubular structure of the gastrointestinal tract situated in between jejunum and cecum. The lining cells of the villi of the ileum of chickens were simple columnar epithelium. The villi of the ileum were long and slender; numerous goblet cells were present among the lining epithelial cells (Figure 1). Histologically, the scattered lymphocytes and unorganized lymphatic nodules were present in the lamina propria and core of the villi. These findings were similar that of Rahman et al. (2003). Lymphocytes in the lamina propria and intraepithelial lymphocytic distribution were increased in concentration in vaccinated group. These findings were similar to those of many authors (Milicevic, 1993; Khan et al., 1996a; Khan et al., 1996b; Karim et al., 2005). The length of mucosa of ileum at cells at D1, D14 and D28 were $154 \pm 0.682 \mu \mathrm{m}, 560 \pm 0.682 \mu \mathrm{m}$ and $1020 \pm 0.725 \mu \mathrm{m}$, respectively (Figure 11). The width of mucosa of ileum at cells at D1, D14 and D28 were $28 \pm 0.025 \mu \mathrm{m}, 107 \pm 0.625 \mu \mathrm{m}$ and $140 \pm 0.365 \mu \mathrm{m}$, respectively (Figure 11). The length and width of mucosa is highest at D28. In this regards, there is no available data. It may be due to aging of broiler.

In the immunohistochemical study, in ileum of chickens, the $\operatorname{IgA} \operatorname{IgG}$ and $\operatorname{IgM}$ positive cells were found in the lamina propria, around the intestinal glands and in the core of the villi of control and vaccinated chickens (Figure 2-7). In vaccinated chickens, IgA positive cells at D1, D14 and D28 were $1.50 \pm 0.289,15.25 \pm 0.629$ and $19.25 \pm 0.854$ respectively (Figure 8); IgG positive cells at D1, D14 and D28 were $1.25 \pm 0.250,19.25 \pm 2.955$ and $26.75 \pm 2.983$ respectively (Figure 9); IgM positive cells D1, D14 and D28 were $1.00 \pm 0.408,15.25 \pm 1.109$ and $7.75 \pm 1.377$, respectively (Figure 10). In control group, IgA positive cells at D1, D14 and D28 were $1.25 \pm$ $0.250,9.00 \pm 0.707$ and $10.25 \pm 0.323$ respectively (Figure 8); IgG positive cells at D1, D14 and D28 were $1.25 \pm$ $0.251,9.50 \pm 0.645$ and $17.75 \pm 0.854$ respectively (Figure 9); IgM positive cells at D1, D14 and D28 were 1.00 $\pm 0.250,8.25 \pm 0.479$ and $3.00 \pm 0.707$ respectively (Figure 10 ).

In the D1 chickens, IgA positive cells $(1.50 \pm 0.289)$, were significantly $(\mathrm{p}<0.01)$ more than the $\operatorname{IgG}(1.25 \pm$ $0.250)$ and $\operatorname{IgM}(1.00 \pm 0.408)$ positive cells. In vaccinated broiler, IgA, IgG and IgM positive cells were peak at $\mathrm{D} 28(19.25 \pm 0.854), \mathrm{D} 28(26.75 \pm 2.983)$ and D14 (15.25 \pm 1.109$)$ respectively.

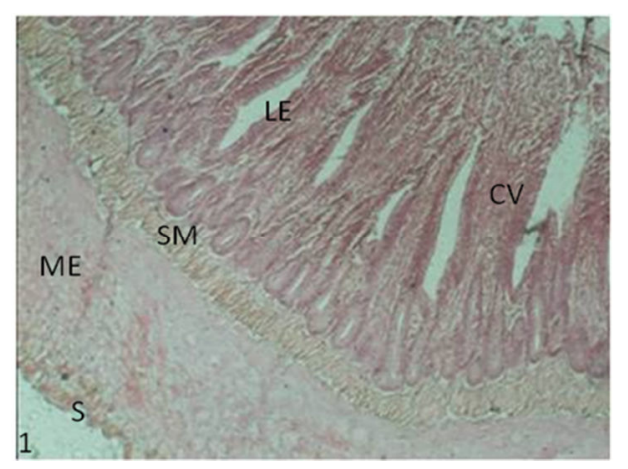

Figure 1. Histological section of Ileum of chicken, showing core of villi (CV), lamina epithelia (LE), intestinal gland (IG), submucosa (SM), muscularis externa (ME) and serosa (S). 100x, H \& E stain.

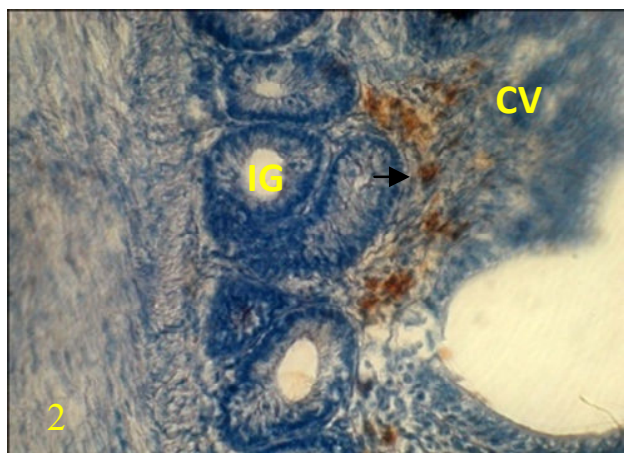

Figure 2. Immunostained section of a ileum of vaccinated chickens at $\mathrm{D} 28$, showing numerous IgGpositive cells (arrows) in the lamina propria (LP). 400x, Indirect immunoperoxidase method. 


\section{A. Masum and others}

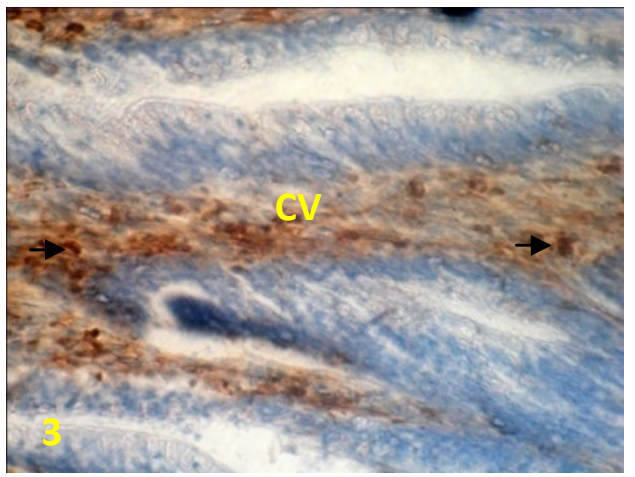

Figure 3. Immunostained section of a ileum of vaccinated broiler at D14, showing numerous IgM- positive cells (arrows) in the core of villi (CV). 400x, Indirect immunoperoxidase method.

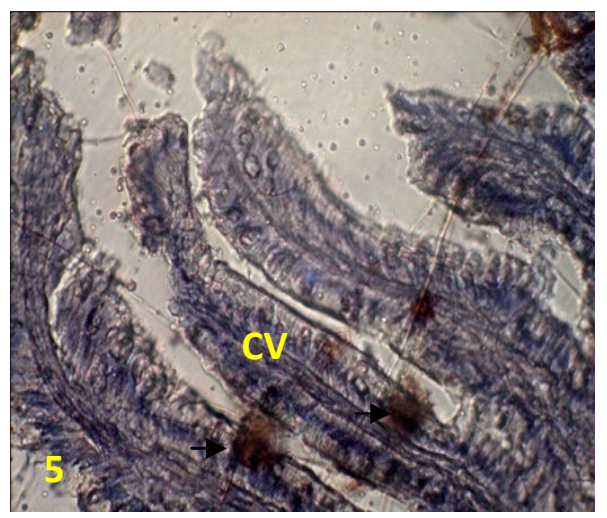

Figure 5. Immunostained section of a ileum of control chickens at D1, showing IgG- positive cell (arrow) in the core of villi (CV). 400x, Indirect immunoperoxidase method.

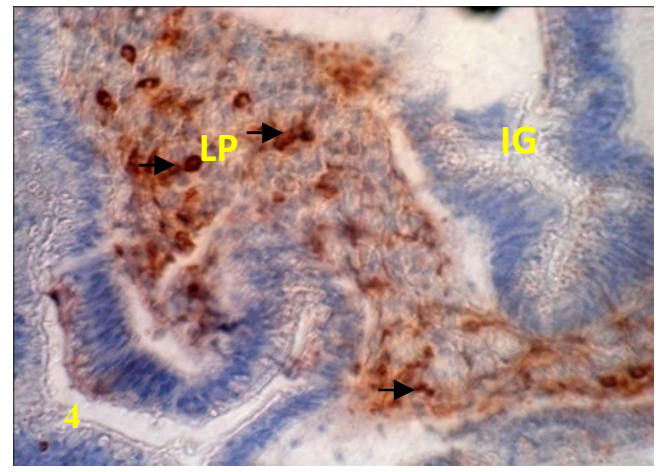

Figure 4. Immunostained section of a ileum of vaccinated chicken at D28, showing numerous IgA- positive cells (arrows) lamina propria (LP) around the intestinal gland (IG). 400x, Indirect immunoperoxidase method.

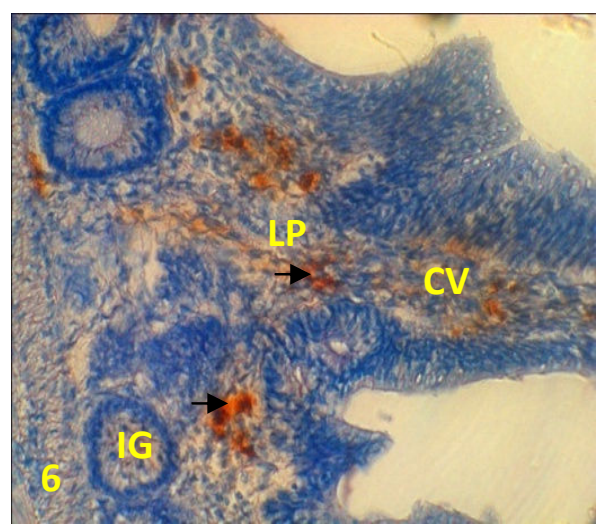

Figure 6. Immunostained section of a ileum of control chicken at D28, showing IgA- positive cells (arrows) lamina propria (LP) around the intestinal gland (IG). 400x, Indirect immunoperoxidase method.

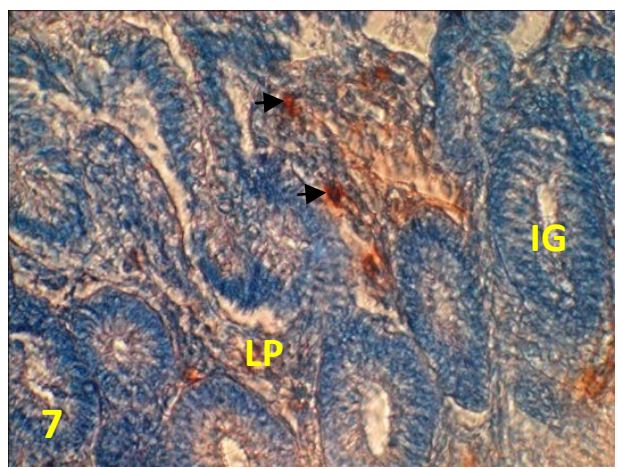

Figure 7. Immunostained section of a ileum of control chicken at D28, showing IgM- positive cells (arrows) lamina propria (LP) around the intestinal gland (IG). 400x, Indirect immunoperoxidase method. 


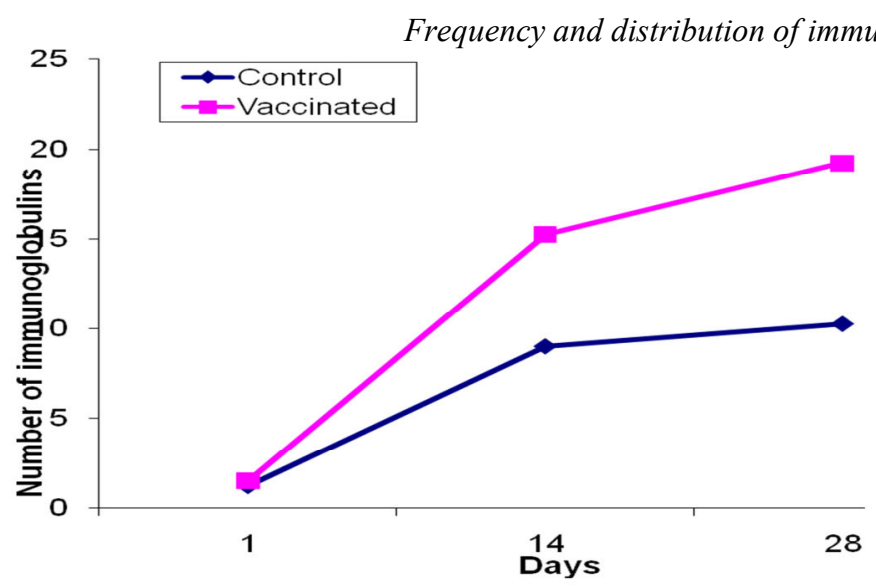

Figure 8. Distribution of IgA positive cells in ileum of chickens during their postnatal growth from D1 to D28. The frequency of $\operatorname{IgA}$ positive cells were more in vaccinated group than control group. The values are given as the mean \pm standard error $(n=4)$.

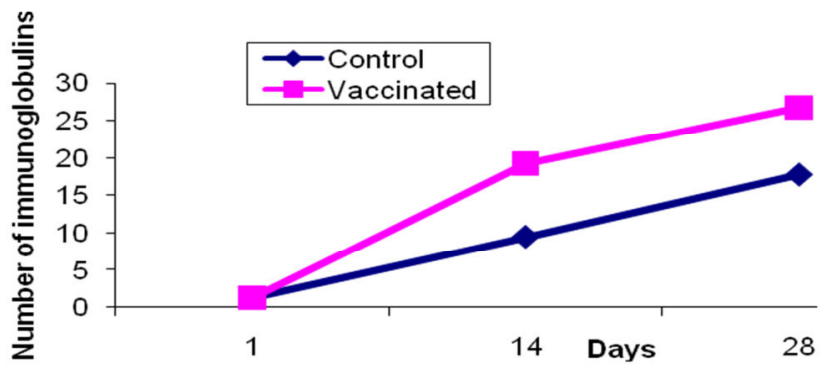

Figure 9. Distribution of IgA positive cells in ileum of chickens during their postnatal growth from D1 to D28. The frequency of IgA positive cells were more in vaccinated group than control group. The values are given as the mean \pm standard error $(n=4)$.

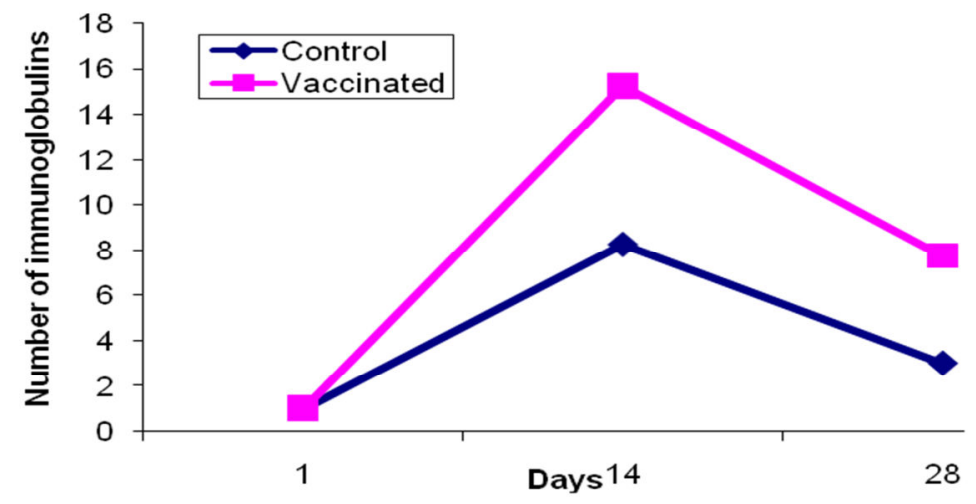

Figure 10. Distribution of IgA positive cells in ileum of chickens during their postnatal growth from D1 to D28. The frequency of IgA positive cells were more in vaccinated group than control group. The values are given as the mean \pm standard error $(\mathrm{n}=4)$. 
M. A. Masum and others

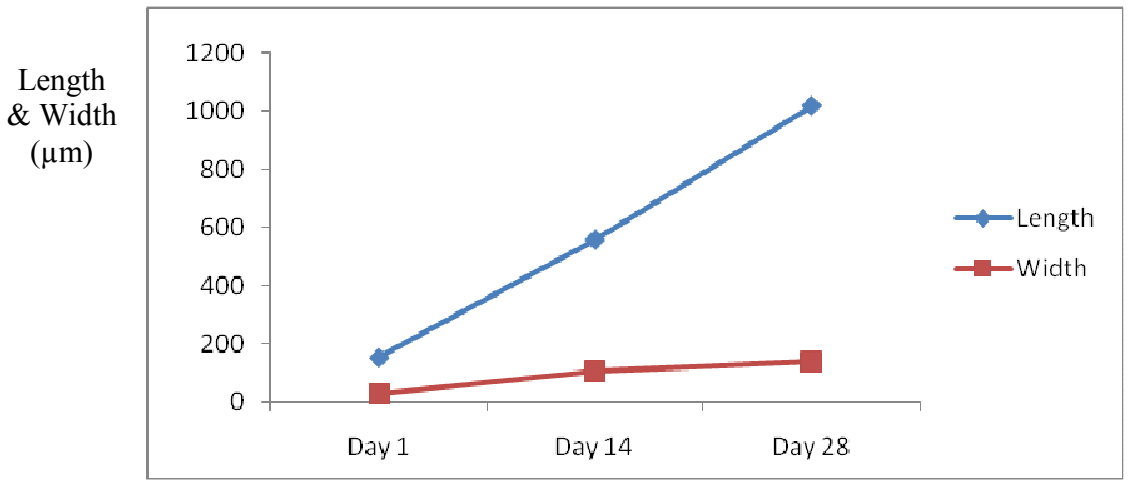

Figure 11. The length $(\mu \mathrm{m})$ and width $(\mu \mathrm{m})$ of lamina mucosa of ileum of broiler from D1 to D28.

\section{ACKNOWLEDGEMENT}

The author wishes to heartfelt thanks to National Scientific, Information and Communication Technology (NSICT) for funding and to carry out this research program.

\section{REFERENCES}

1. Cortan RS, Kumar V and Robbin S (1998). Robbin's Pathogenic Basis of Disease. $4^{\text {th }}$ edn. Philadelphia, London, Toronto. W. B. Saunders pp. 163-164.

2. Gridley MF (1960). Manual of Histologic and Special Staining Technique. McGraw-Hill Book Company. INC, New York, pp. 28-29, 82-83.

3. Islam MN, Khan MZI, Jahan MP, Karim MR and Yasuhiro K (2008). Comparative studies of mucosa and immunoglobulin (Ig) containing plasma cells in the gastrointestinal tract of broiler and native chickens of Bangladesh. Journal of Poultry Science 45: 125-131.

4. Jeurissen SHM, Janse EM, Koch G and Boer GF (1989). Postnatal development of mucosa-associated lymphoid tissues in chickens. Cell Tissue 258: 119-124.

5. Karim MR, Khan MZI and Hague Z (2005). The dynamics of immunocompetent in the major lymphoid organs and mucosa-associated lymphoid tissues of the chemotherapy treated chickens. Journal of Bangladesh Socio-Agricultural Science and Technology 2(324): 5-8.

6. Khan MZL, Hashimoto Y, Konnol A, Kon Y and Iwanaga T (1996). Development of T-lymphocyte subpopulations in the postnatal chicken oviduct. Cell Tissue 284: 317-325.

7. Khan MZI, Hashimoto Y, Swami Y and 1wanaga T (1997). Postnatal development of B-lymphocytes and immunoglobulin-continuing plasma cells in the chicken oviduct: studies on the cellular distribution and influence of sex hormones. Veterinary Immunology and Immunopathology 56: 329-338.

8. Khan MZI, Hashimoto Y and Asaduzzaman M (1998) Development of T-cell sub-populations in postnatal chicken lymphoid organs. Vetrinarski Arhive 68(5): 183-189.

9. McDonald TT and Spencer J (1994). Gut-associated lymphoid tissue. In: Hand Book of Mucosal immunology. Academic press. San Diego, California. pp. 420-421.

10. McGhee JR, Mestecky J, Dertzbaugh MT, Eldridge JH, Hirasawa MA and Viney JL (1997). The anatomical basis of intestinal immunity. Immunology Review. 156: 145-166.

11. Milicevic Z and Milicevic N (1993). Structure of the bursa of Fabricius and immune response of Brucella abortus in the chicken after neonatal gonadectomy. Poultry Science. 7(2): 129-133.

12. Mowat AM and Viney JL (1997). The anatomical basis of intestinal immunity. Immunology Review 156: 145-166.

13. Rahman ML, Islam MAR, Asaduzzaman M and Khan MZI (2003). Lymphoid tissues in the digestive tract of Deshi Chicken (Gallus domesticus) in Bangladesh. Pakistan Journal of Biological Science 6(13): 11451150 . 